\title{
AVALIAÇÃO DAS CONDIÇÕES DE SEGURANÇA DO TRABALHO NA COLHEITA E TRANSPORTE FLORESTAL EM PROPRIEDADES RURAIS FOMENTADAS NO ESTADO DO ESPÍRITO SANTO ${ }^{1}$
}

\author{
Juliana Lorensi do Canto ${ }^{2}$, Carlos Cardoso Machado ${ }^{3}$, Amaury Paulo de Souza ${ }^{3}$, Alencar Garlet ${ }^{4}$, Rosa \\ Maria Miranda Armond Carvalho ${ }^{5}$ e Rommel Noce ${ }^{2}$
}

\begin{abstract}
RESUMO - Este trabalho foi desenvolvido com informações obtidas de 70 proprietários rurais fomentados, responsáveis por 90 contratos de fomento florestal, com o objetivo de caracterizar as condições de segurança do trabalho na colheita e transporte florestal, em propriedades rurais fomentadas no Estado do Espírito Santo. A área fomentada por contrato variava entre 1,5 e 100,0 ha, sendo de até 30 ha em $86,7 \%$ dos contratos e com relevo montanhoso em $61,2 \%$. A colheita e transporte florestais foram terceirizados em 70 e $80 \%$ dos contratos amostrados, respectivamente, e realizados por conta dos proprietários nos demais. A maioria dos prestadores de serviço terceirizados era contratada informalmente. Foi empregada a mão-de-obra contratada na maioria dos contratos com colheita própria, sendo a maior parte não qualificada e contratada informalmente. Grande parte dos trabalhadores deslocava-se por conta própria até o local de colheita. Ocorreram acidentes de trabalho em $16,3 \%$ dos contratos, sendo $60 \%$ na colheita e transporte florestal próprios. A maioria dos acidentes aconteceu na atividade de corte e atingiu, principalmente, os membros inferiores e superiores do trabalhador acidentado. Os trabalhadores não utilizavam equipamentos de proteção individual em $62,1 \%$ dos contratos com colheita própria e em $23,0 \%$ dos terceirizados. Observou-se carência de material de primeiros socorros, bem como falta de instrução para o socorro de trabalhadores acidentados na colheita florestal.
\end{abstract}

Palavras-chave: Fomento florestal, colheita florestal e acidentes de trabalho.

\section{EVALUATION OF WORK SAFETY CONDITIONS OF TIMBER HARVESTING AND TRANSPORT IN FOMENTED FARMS OF THE STATE OF ESPÍRITO SANTO, BRAZIL}

\begin{abstract}
This research was developed with data obtained from 70 fomented farm owners in the State of Espírito Santo, Brazil, who were responsible for 90 forest contracts distributed in 22 cities of the State. The area fomented per contract ranged from 1.5 to 100 hectares, being $84.8 \%$ of contracts up to 30 ha and $59.8 \%$ with mountainous relief. Timber harvesting and log transport were outsourced and carried out by a subcontractor in $70 \%$ and $80 \%$ of the contracts respectively, whereas in the remaining contracts, they were carried out by the farm owners themselves. Most of the subcontractors were not formally hired with a signed contract. The workers of most contracts with timber harvesting carried out by farm owners were not formally hired and not qualified for the job. Great part of the workers used their own means of transport to the work place. Work accidents occurred in $16.3 \%$ of the contracts, with $60 \%$ of them taking place during
\end{abstract}

\footnotetext{
${ }^{1}$ Recebido em 22.10.2006 e aceito para publicação em 13.03.2007.

${ }^{2}$ Programa de Pós-Graduação em Ciência Florestal da UFV. E-mail: <jlcanto@ terra.com.br>.

${ }^{3}$ Departamento de Engenharia Florestal da UFV. E-mail: <machado@ufv.br>.

${ }^{4}$ Laboratório de Produtos Florestais do IBAMA. E-mail: <alencar.galet@ibama.gov.br>.

${ }^{5}$ Programa de Pós-Graduação em Ciências Florestais da Universidade Federal de Lavras.
} 
timber harvesting and log transport by the farm owners. Most accidents took place in logging activities and causing injuries mainly to workers' inferior and superior limbs. The workers did not use personal protective equipment in $62.1 \%$ of the contracts with timber harvesting carried out by the farm owner and in $23 \%$ of outsourced contracts. It was verified lack of first aid materials and training to help injured workers during timber harvesting.

Keywords: Fomented forest, timber harvesting and work accidents.

\section{INTRODUÇÃO}

O fomento florestal é um instrumento estratégico que promove a integração dos produtores rurais à cadeia produtiva e lhes proporciona vantagens econômicas, sociais e ambientais. Além da ampliação da base florestal no raio econômico de transporte para suprir a demanda de matéria-prima para as indústrias, o fomento florestal, como atividade complementar na propriedade rural, viabiliza o aproveitamento de áreas degradadas, improdutivas, subutilizadas e inadequadas à agropecuária, propiciando alternativa adicional de renda ao produtor rural (SIQUEIRA et al., 2004).

A atividade florestal, contudo, em muitos casos é pioneira em propriedades rurais (CASTRO FILHO, 1991). A colheita e transporte da madeira foram apontados, por produtores rurais fomentados no Estado do Espírito Santo, como a grande desvantagem do programa de fomento florestal. Entre os fatores que dificultam a colheita e o transporte florestal, os produtores apontaram a falta de máquinas e equipamentos adequados na propriedade e o alto risco de acidentes inerente a essas atividades realizadas de forma manual ou semimecanizada (OLIVEIRA, 2003).

A colheita florestal é considerada um trabalho pesado devido à grande exigência física requerida ao trabalhador, principalmente quando realizada de forma manual ou semimecanizada, e com alto risco de acidentes (FIEDLER et al., 1998). As condições e o ambiente de trabalho na colheita florestal têm aspectos particulares, pois os locais de trabalho são temporários e os trabalhadores atuam expostos a condições climáticas adversas, que aumentam o risco de acidentes (MINETTI et al., 1998).

Além da pouca experiência dos produtores rurais na área de silvicultura, deve-se considerar que em áreas florestais de pequena escala os riscos de acidentes tendem a ser altos devido a equipamentos inadequados e à falta de mecanismos de segurança, trabalhadores desqualificados e inexperientes e de conhecimento sobre os riscos inerentes à atividade. Nas operações de colheita florestal ocorrem muitos acidentes, e as principais causas têm sido a falta de experiência e de treinamento, a utilização de máquinas e ferramentas inadequadas e uso dos equipamentos de proteção individual (LOPES et al., 1999).

Tendo em vista que os acidentes são considerados indicadores das condições de trabalho, estes foram levantados diretamente dos proprietários rurais, pois a maioria deles não é relatada ou notificada nos sistemas de registro, uma vez que não são amparados por compensações trabalhistas (trabalhadores informais), não sendo, portanto, considerados nos levantamentos de estatísticas oficiais. Assim, o objetivo deste trabalho foi caracterizar as condições de trabalho, especificamente em questões de segurança, em atividades de colheita e transporte florestal de propriedades rurais fomentadas no Estado do Espírito Santo.

\section{MATERIAL E MÉTODOS}

\subsection{População e amostra}

A população deste trabalho refere-se aos contratos de fomento estabelecidos entre uma empresa florestal e proprietários rurais do Estado do Espírito Santo que se encontravam em processo de colheita e transporte da madeira, entre os meses de outubro de 2004 e outubro de 2005. Nesse período, havia 104 contratos, distribuídos em 22 municípios do Estado, em processo de colheita florestal e transporte da madeira até um dos cinco depósitos regionais da empresa. Os 22 municípios abrangidos neste trabalho foram: Águia Branca, Alfredo Chaves, Alto Rio Novo, Aracruz, Baixo Guandu, Boa Esperança, Colatina, Conceição da Barra, Conceição do Castelo, Domingos Martins, Ibiraçu, Itaguaçu, Linhares, Mantenópolis, Marechal Floriano, Pancas, Pinheiros, Rio Bananal, Santa Maria de Jetibá, Santa Teresa, São Domingos do Norte e São Mateus.

O número mínimo de contratos a serem amostrados foi calculado segundo a expressão para populações 
finitas proposta por Richardson (1985):

$$
\mathrm{n}=\frac{\sigma^{2} \cdot \mathrm{p} \cdot \mathrm{q} \cdot \mathrm{N}}{\mathrm{E}^{2}(\mathrm{~N}-1)+\sigma^{2} \cdot \mathrm{p} \cdot \mathrm{q}}
$$

em que:

$\mathrm{n}=$ tamanho da amostra;

$\sigma=$ nível de confiança, em número de desvios;

$\mathrm{p}=$ proporção da característica pesquisada no universo, em porcentagem;

$\mathrm{q}=$ proporção do universo que não possui a característica pesquisada, em porcentagem;

$$
\begin{aligned}
& \mathrm{N}=\text { tamanho da população; e } \\
& \mathrm{E}=\text { erro de estimação permitido. }
\end{aligned}
$$

Supôs-se que a proporção da característica pesquisada no universo fosse de $50 \%$, ou seja, o caso mais desfavorável para a estimação, pois é aquele em que a amostra deve ser maior. Nesse caso, a proporção do universo que não possui a característica pesquisada é de $50 \%$. Considerando um nível de confiança de $95 \%$, equivalente a dois desvios, e um erro de estimação de 5\%, obteve-se o tamanho mínimo da amostra composta por 83 contratos de fomento florestal. Contudo, foram amostrados 90 contratos.

\subsection{Obtenção e análise de dados}

Os dados foram obtidos nos meses de setembro e outubro de 2005, por meio de questionários específicos, contendo perguntas abertas e fechadas acerca das atividades de colheita e transporte florestal. Os questionários foram aplicados, em forma de entrevista, aos titulares dos contratos de fomento florestal ou, em alguns casos, ao representante ou pessoa ligada ao titular que estava à frente das atividades relacionadas ao contrato. Os 90 contratos amostrados corresponderam a 70 proprietários rurais fomentados, pois houve casos em que um proprietário possuía mais de um contrato ou era responsável por contratos de familiares, sendo estes apenas os titulares legais. Os dados obtidos foram, posteriormente, tabulados em planilha eletrônica do Microsoft Excel 2002, para realização das análises.

\section{RESULTADOS E DISCUSSÃO}

\subsection{Os contratos de fomento florestal}

O tamanho da área fomentada por contrato variou entre 1,5 e 100,0 ha, sendo de até 30 ha em $86,7 \%$ deles e com relevo montanhoso em 61,2\% (Quadro 1). Acolheita e o transporte florestal foram terceirizados em $70 \%$ e $80 \%$ dos contratos, respectivamente, e realizados por conta dos proprietários nos demais.

\subsection{Características do trabalho}

A colheita florestal compreende um conjunto de atividades composto pelas etapas de corte (derrubada das árvores, desgalhamento e traçamento em toretes), extração dos toretes e carregamento dos veículos de transporte.

Na colheita florestal terceirizada, as atividades de derrubada das árvores e traçamento dos toretes foram realizadas com motosserras. Em 41,0\% dos contratos, os toretes foram traçados com $3 \mathrm{~m}$ de comprimento, em $57,4 \%$ deles com $2,20 \mathrm{~m}$ de comprimento e nos restantes com $2,40 \mathrm{~m}$. O desgalhamento foi executado com motosserras em 70,5\% dos contratos, com instrumentos manuais (machados e facões) em $10,0 \%$ deles e de forma desconhecida pelos proprietários nos contratos restantes. A extração dos toretes foi manual em 55,7\% dos contratos e mecanizada (por meio de trator autocarregável e trator com guincho) nos demais. O carregamento dos veículos de transporte foi manual em $62,3 \%$ dos contratos e mecanizado nos demais. O transporte florestal terceirizado foi realizado com caminhões de dois e três eixos e caminhões articulados.

$\mathrm{Na}$ colheita florestal própria, as atividades de derrubada das árvores e traçamento dos toretes foram executadas com motosserras. Em 17,2\% dos contratos, os toretes foram traçados com $3 \mathrm{~m}$ de comprimento, em 79,3\% deles com 2,20 m de comprimento e nos restantes com 2,40 m. O desgalhamento foi realizado com motosserras em $48,3 \%$ dos contratos e com instrumentos manuais (machados e facões) nos restantes. A extração dos toretes foi manual em $96,6 \%$ dos contratos e mecanizada por meio de trator autocarregável nos restantes.

Quadro 1 - Distribuição porcentual dos contratos por classe de tamanho e relevo da área

Table 1 - Percentage distribution of the contracts by size class and relief of the area

\begin{tabular}{lcccc}
\hline Classes de & \multicolumn{3}{c}{ Tipos de Relevo } & Total \\
\cline { 2 - 4 } área (ha) & Plano & Ondulado & Montanhoso & \\
\hline$<10$ & 4,4 & 7,8 & 27,8 & 40,0 \\
10 a 29,9 & 7,8 & 12,2 & 26,7 & 46,7 \\
$>30$ & 4,4 & 2,2 & 6,7 & 13,3 \\
Total & 16,6 & 22,2 & 61,2 & 100 \\
\hline
\end{tabular}

R. Árvore, Viçosa-MG, v.31, n.3, p.513-520, 2007 
O carregamento dos veículos de transporte foi manual em $96,6 \%$ dos contratos e mecanizado nos restantes. O transporte florestal próprio foi realizado com caminhões de dois e três eixos.

\subsection{Mão-de-obra empregada}

\subsubsection{Colheita florestal terceirizada}

Dos proprietários que terceirizaram a colheita florestal, destaca-se que 69,6\% não firmaram contrato por escrito com os prestadores de serviço. Nessas circunstâncias, deve-se atentar para os riscos advindos da contratação informal, principalmente pelo fato de os proprietários virem a ser responsabilizados juridicamente por danos civis ou lesões corporais. A falta de um contrato formal e expresso descaracteriza a relação legal entre as partes e não evidencia que os trabalhadores estão sob a responsabilidade de supervisão de terceiros (QUEIROZ, 1998). Os contratos devem definir as responsabilidades e os deveres das partes nos termos da legislação nacional e especificar os requisitos de segurança e saúde, assim como as sanções e penalidades em caso de não cumprimento.

Os trabalhadores dos prestadores de serviço tinham uma jornada média de trabalho de nove horas, de segunda a sexta-feira, perfazendo um total de 45 horas semanais.

O deslocamento dos trabalhadores dos prestadores de serviço até o local da colheita foi realizado por ônibus em $29,5 \%$ dos contratos; por automóveis em 21,3\% dos contratos; por motocicletas em $4,9 \%$ dos contratos; a pé em $9,8 \%$ dos contratos; e por caminhões em $6,6 \%$ dos contratos. Observou-se que grande parte dos trabalhadores se deslocou por conta própria até o local de colheita. Em 13,1\% dos contratos não houve deslocamento diário dos trabalhadores até o local de colheita, pois eles ficaram hospedados na casa do proprietário $(75,0 \%)$, em casa alugada pelo prestador de serviço (12,5\%) e em acampamento estabelecido no local de colheita (12,5\%). Os proprietários referentes aos $14,8 \%$ dos contratos restantes não souberam responder quanto à forma de deslocamento dos trabalhadores.

Os trabalhadores dos prestadores de serviço receberam ordens dos próprios prestadores de serviço ou de seus encarregados em $95,1 \%$ dos contratos e dos proprietários em 4,9\% deles, o que descaracteriza a terceirização da atividade.

\subsubsection{Colheita florestal própria}

Na colheita florestal própria, empregou-se mãode-obra contratada em $63,8 \%$ contratos, familiar em $22,4 \%$, de meeiros em $6,9 \%$ e de vizinhos em $6,9 \%$.

Os trabalhadores contratados não tinham vínculo empregatício formal com os proprietários em 51,4\% dos contratos, e no restante esse vínculo empregatício era através de carteira de trabalho $(32,4 \%)$ ou contrato temporário (16,2\%). Considerando a soma dos trabalhadores contratados sem vínculo empregatício, dos trabalhadores familiares, meeiros e vizinhos, temse o total de $69 \%$ de contratos com mão-de-obra informal.

Cerca de $73 \%$ dos proprietários não fizeram nenhuma exigência na contratação da mão-de-obra. O restante exigiu experiência, mas não requereu comprovação. Nesse sentido, destaca-se que o emprego de pessoas despreparadas, além de ser um problema social dado ao risco de acidentes, compromete também os aspectos econômicos da atividade, pois os recursos humanos devidamente capacitados são fatores decisivos no aumento da produtividade. Todo trabalhador, ao se ingressar na colheita florestal, deveria ser previamente treinado para desempenhar a função com maior produtividade; menor esforço físico, resultante da utilização de técnicas de trabalho adequadas; maior conscientização em relação ao uso de equipamentos de proteção individual; e menor de risco de acidentes (LOPES et al., 1997). Esse treinamento se faz mais necessário ainda para aqueles trabalhadores que nunca tiveram nenhum contato com a atividade florestal (FIEDLER et al., 2000). Além disso, para operadores de motosserras o treinamento é obrigatório, de acordo com a NR 12 (Norma Regulamentadora do Ministério do Trabalho e Emprego) (BRASIL, 1978a).

Na colheita própria, a jornada média de trabalho era de oito horas, de segunda a sexta-feira, perfazendo um total de 40 horas semanais.

O deslocamento dos trabalhadores contratados até o local da colheita era realizado por automóveis em $35,2 \%$ dos contratos, por caminhões em $16,2 \%$, a pé em $16,2 \%$, e por motocicletas em $10,8 \%$. Observouse que a maioria dos trabalhadores contratados deslocouse por conta própria até o local de colheita. Em 21,6\% dos contratos não houve se deslocou diário dos trabalhadores até o local de colheita, pois eles ficaram hospedados na casa do proprietário. $\mathrm{O}$ deslocamento 
dos trabalhadores meeiros até o local da colheita foi realizado por automóveis e o dos trabalhadores vizinhos dos proprietários, por automóveis em $50 \%$ dos contratos e a pé nos outros $50 \%$, comprovando que esses operários residiam próximo à área do contrato.

Os trabalhadores contratados recebiam ordens dos proprietários em $67,6 \%$ dos contratos e dos encarregados dos proprietários em $27,0 \%$ deles. Entretanto, em 5,4\% dos contratos os entrevistados responderam que os trabalhadores contratados não recebiam ordens. Salienta-se que a existência de um coordenador é necessária para a orientação dos trabalhadores nas tarefas que devem ser realizadas. O coordenador desempenha papel estrutural fundamental para a saúde do grupo, que é o de referência de direito e ordem e a quem se devem justificativas dos comportamentos profissionais (SILVA, 1995).

As ordens dadas aos trabalhadores contratados tinham frequiência diária em $67,6 \%$ dos contratos, semanal em $21,6 \%$ e eventual em 10,8\%. Muitas vezes, os acidentes são causados devido à falta de planejamento do trabalho, falta de qualificação e experiência dos supervisores e organização e supervisão precárias (OIT, 2005).

Os proprietários não fizeram nenhum planejamento prévio das operações de colheita florestal em 55,2\% dos contratos. A sequiência de atividades mal planejadas e a má distribuição de horários e atividades estão entre os problemas que podem causar condições inseguras (LARA, 1982).

\subsection{Acidentes de trabalho}

Ocorreram acidentes de trabalho em 15 dos 90 contratos amostrados, o que representa um porcentual de $16,7 \%$ de contratos com ocorrência de acidentes. Desses acidentes, $60 \%$ aconteceram em contratos com colheita e transporte florestal próprios e $40 \%$, em terceirizados.

Os proprietários rurais fomentados declararam que não tinham experiência em colheita florestal em 55,6\% dos contratos próprios com ocorrência de acidentes.

Dos acidentes ocorridos na colheita e transporte florestal próprios, 33,4\% envolveram mão-de-obra familiar, 22,2\% meeira, 22,2\% contratada informalmente e $22,2 \%$ contratada formalmente. E, dos acidentes ocorridos na colheita e transporte florestal terceirizados, $50 \%$ envolveram prestadores de serviço sem contratação formal.

A Figura 1 ilustra a composição porcentual dos acidentes ocorridos por atividade da colheita e transporte florestal e a Figura 2, a composição porcentual dos acidentes por atividade e por parte do corpo atingida. A maioria dos acidentes ocorreu na atividade de corte (derrubada, desgalhamento e traçamento) e atingiu, principalmente, os membros inferiores e superiores do trabalhador acidentado.

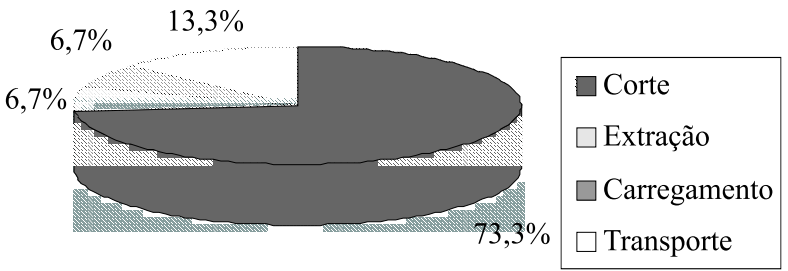

Figura 1 - Porcentual dos acidentes ocorridos por atividade da colheita e transporte florestal.

Figure 1 - Percentage of work accidents occurred during timber harvesting and log transport.

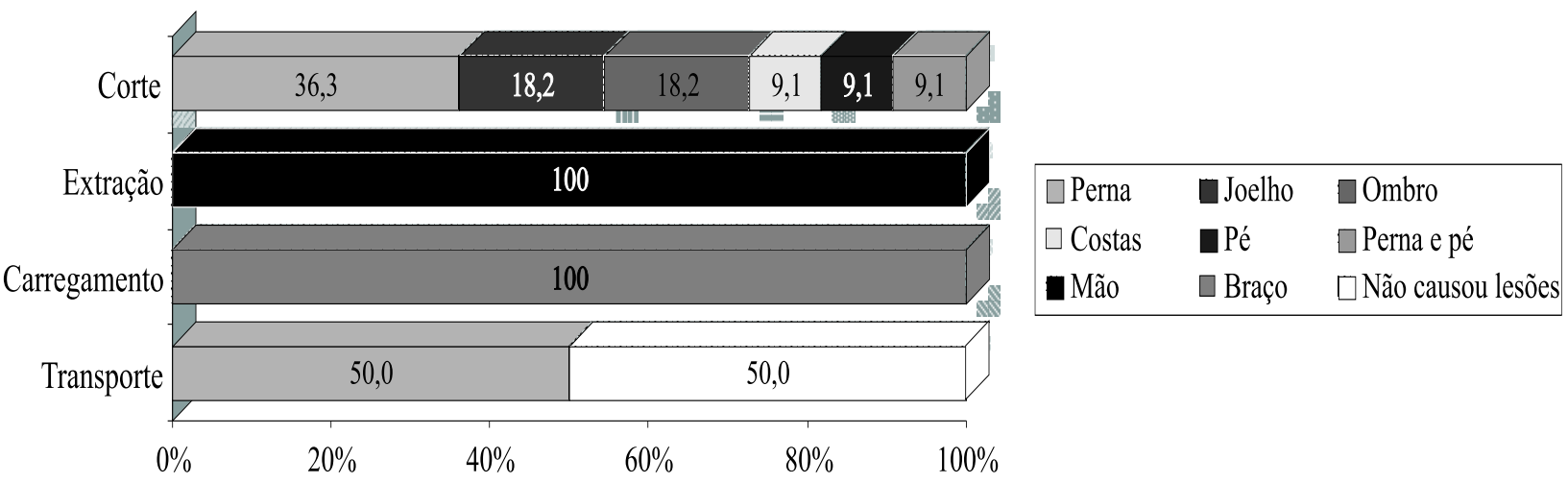

Figura 2 - Porcentual dos acidentes de trabalho ocorridos por atividade da colheita e transporte florestal e por parte do corpo atingida. Figure 2-Percentage of work accidents occurred per each activity of timber harvesting and log transport and per body part injured. 
O socorro aos trabalhadores acidentados na colheita e transporte florestal terceirizados foi prestado pelos colegas de trabalho, pelo encarregado ou pelo responsável pela prestação de serviço em $50 \%$ dos acidentes. Em 33,3\% deles, o socorro foi prestado pelo proprietário e, em $16,7 \%$, por outras pessoas que se encontravam no local. Na colheita e transporte florestal próprios, o socorro aos trabalhadores acidentados foi prestado pelo proprietário em $55,6 \%$ dos acidentes e pela família em $44,4 \%$ deles.

Segundo os entrevistados, os principais motivos dos acidentes ocorridos foram falta de atenção e fatalidade. Entretanto, os trabalhadores não estavam usando nenhum equipamento de proteção individual em 76,9\% dos contratos com ocorrência de acidentes nas atividades da colheita florestal (corte, extração e carregamento). Os entrevistados responderam que, na atividade de corte, $54,5 \%$ dos acidentes aconteceram por falta de atenção, $36,4 \%$ por fatalidade e $9,1 \%$ por falta de experiência do trabalhador. Cabe relatar que um dos acidentes ocorridos no corte se referia à picada de ofídios. Na extração e carregamento, $100 \%$ dos acidentes ocorreram por fatalidade. E, no transporte, $50 \%$ foram por problemas técnicos no veículo e $50 \%$ por consumo de bebida alcoólica pelo motorista.

A atribuição dos acidentes à fatalidade é justificada pelo desconhecimento ou conhecimento parcial dos proprietários quanto aos riscos inerentes às atividades de colheita florestal, pois se pode afirmar que nenhum acidente ocorre por fatalidade. Os acidentes são causados por atos inseguros, condições inseguras ou os dois fatores em conjunto. Os atos inseguros são práticas de procedimentos que contrariam as normas de segurança, criando condições para que o acidente aconteça. Além disso, as condições do local ou ambiente de trabalho também podem oferecer riscos (FUNDACENTRO, 1978; LARA, 1982). Para Iida (1990), os acidentes geralmente resultam de interações inadequadas entre o homem, a tarefa e o seu ambiente.

O tempo médio que os trabalhadores acidentados na atividade de corte ficaram impossibilitados de trabalhar foi de 17,5 dias, sendo o máximo de quatro meses. No carregamento dos veículos de transporte foi de quatro meses e no transporte, de 15 dias. Na extração não houve acidentes que impossibilitassem o acidentado de trabalhar.

R. Árvore, Viçosa-MG, v.31, n.3, p.513-520, 2007

\footnotetext{
R. Árvore, Viçosa-MG, v.31, n.3, p.513-520, 2007
}

Na colheita terceirizada, os prestadores de serviço mantinham veículos disponíveis para a prestação de socorro em $91,8 \%$ dos contratos. Os proprietários referentes a $3,3 \%$ dos contratos não souberam responder, e nos $4,9 \%$ restantes não havia veículos de transporte no local da colheita para uma possível prestação de socorro.

Na colheita própria, os proprietários possuíam veículos disponíveis para a prestação de socorro em $89,7 \%$ dos contratos. Contudo, em $69 \%$ dos contratos não havia material de primeiros socorros básicos. Além disso, nenhum dos proprietários rurais fomentados teve algum curso sobre primeiros socorros ou prevenção de acidentes.

\subsection{Equipamentos de proteção individual (EPIs)}

Os trabalhadores não utilizavam nenhum equipamento de proteção individual (EPI) em 23,0\% dos contratos com colheita terceirizada e em $62,1 \%$ dos contratos com colheita própria (Quadro 2). Esses resultados surpreendem pelo elevado porcentual de trabalhadores que não fazem uso de EPI nas atividades de colheita florestal, apesar de a sua necessidade ser evidente.

Conforme a NRR 4 (Norma Regulamentadora Rural do Ministério do Trabalho e Emprego) (BRASIL, 1988), o empregador rural é obrigado a fornecer EPIs adequados às atividades desempenhadas. Na colheita florestal, o capacete é essencial para a proteção do impacto proveniente da queda de galhos. O protetor facial é destinado à proteção dos olhos e da face contra lesões ocasionadas por partículas de madeiras resultante das atividades de derrubada, desgalhamento e traçamento. As luvas são necessárias principalmente nas atividades de extração e carregamento manuais. Botas de cano longo ou botinas com perneiras, além de serem fundamentais para a proteção de operadores de motosserras, são importantes para trabalhadores do campo, que estão sujeitos a acidentes com animais peçonhentos. O uso do protetor auricular também se faz útil nas atividades de corte, pois os operadores de motosserra estão sujeitos à influência de um nível de ruído superior ao permitido pela legislação brasileira, o qual, para uma jornada de trabalho de oito horas, é de 85 decibéis, conforme a NR 15 (Norma Regulamentadora do Ministério do Trabalho e Emprego) (BRASIL, 1978b). Entretanto, observou-se que em nenhum contrato de fomento florestal os trabalhadores dispunham de todos esses equipamentos citados. 
Quadro 2 - Equipamentos de proteção individual (EPIs) utilizados na colheita florestal Table 2 - Personal protective equipment (PPE) used during timber harvesting

\begin{tabular}{|c|c|c|c|}
\hline \multirow[t]{2}{*}{ EPIs } & \multicolumn{2}{|c|}{ Colheita Florestal } & \multirow[t]{2}{*}{ Total } \\
\hline & Terceirizada & Própria & \\
\hline$\overline{\text { Nenhum }}$ & 23,0 & 62,1 & 35,7 \\
\hline Capacete, luvas, protetor facial e auricular & 18,0 & - & 12,2 \\
\hline Capacete & 11,5 & 10,3 & 11,1 \\
\hline Capacete e luvas & 9,8 & 10,3 & 10,0 \\
\hline Luvas & 8,2 & 13,8 & 10,0 \\
\hline Capacete e protetor auricular & 3,3 & - & 2,2 \\
\hline Protetor auricular & 3,3 & - & 2,2 \\
\hline Perneira & 3,3 & - & 2,2 \\
\hline Protetor facial & - & 3,5 & 1,1 \\
\hline Capacete, luvas e protetor facial & 1,6 & - & 1,1 \\
\hline Não souberam responder & 18,0 & - & 12,2 \\
\hline Total & $100 \%$ & $100 \%$ & $100 \%$ \\
\hline
\end{tabular}

\section{CONCLUSÕES}

- Constatou-se que os prestadores de serviço da maioria dos contratos com colheita terceirizada $(69,6 \%)$ e os trabalhadores da maioria dos contratos com colheita própria (69\%) foram contratados informalmente.

- Observou-se que os trabalhadores da colheita própria possuíam baixa qualificação e os proprietários rurais fomentados tinham pouca experiência no planejamento e orientação do trabalho de colheita florestal, evidenciando-se a necessidade de capacitação e treinamento de mão-de-obra para a atividade.

- Em $23,0 \%$ dos contratos terceirizados e em $62,1 \%$ dos contratos próprios, os trabalhadores não utilizavam nenhum EPI, e em nenhum contrato os trabalhadores dispunham de todos os EPIs necessários às atividades de colheita florestal.

- Ocorreram acidentes de trabalho em $16,3 \%$ dos contratos, com a ressalva de que $60 \%$ deles ocorreram em colheita e transporte próprios e em 76,9\% deles os trabalhadores não estavam usando nenhum EPI.

- Verificou-se carência de material de primeiros socorros e falta de instrução para o atendimento de trabalhadores acidentados na colheita florestal.

- Evidenciou-se a necessidade de conscientização dos proprietários rurais fomentados e dos trabalhadores sobre o risco de acidentes inerentes à colheita florestal e a importância da utilização de equipamentos de proteção individual, bem como de instrução sobre como trabalhar de forma segura.

\section{AGRADECIMENTOS}

Ao Conselho Nacional de Desenvolvimento Científico e Tecnológico (CNPq) e à Empresa Aracruz Celulose, pelo apoio disponibilizado.

\section{REFERÊNCIAS}

CASTRO FILHO, F. P. Política de fomento florestal do estado de Minas Gerais. In: SEMINÁRIO SOBREASPECTOS ECONÔMICOS, SOCIAIS E AMBIENTAIS DO FOMENTO FLORESTAL, 1990, Belo Horizonte. Anais... Viçosa, MG: UFV/DEF/ SIF, 1991. p.18-28.

FIEDLER, N. C. et al. Avaliação da carga de trabalho físico exigida em operações de colheita florestal. Revista Árvore, v.22, n.4, p.535-543, 1998.

FIEDLER, N.C. et al. Análise de fatores humanos e condições de trabalho em operações de colheita florestal. Revista Árvore, v.24, n.2, p.135-142, 2000.

FUNDACENTRO. Manual de segurança, higiene e medicina do trabalho rural. São Paulo: 1978. 185p.

IIDA, I. Ergonomia: projeto e produção. São Paulo: Edgard Blücher, 1990. 465p.

LARA, J. E. Higiene e segurança do trabalho. Viçosa, MG: Imprensa Universitária UFV, 1982.53p.

R. Árvore, Viçosa-MG, v.31, n.3, p.513-520, 2007 
LOPES, E. S. et al. Avaliação do treinamento de operadores de motosserra no corte florestal - um estudo de caso. Revista Árvore, v.21, n.3, p.369-376, 1997.

LOPES, E. S. et al. Influência de alguns aspectos ergonômicos e sociais no planejamento da colheita florestal. In: SIMPÓSIO BRASILEIRO COLHEITA E TRANSPORTE FLORESTAL, 4., 1999. Campinas. Anais... Viçosa: SIF/UFV, 1999. p.322-330.

MINETTI, L.J. et al. Análise da influência de fatores climáticos no corte florestal com motosserra. Revista Árvore, v.22, n.4, p.527-534, 1998.

BRASIL. Ministério do Trabalho e Emprego.. Portaria $\mathrm{n}^{\circ} 3.067$, de 12 de abril 1988. Norma Regulamentadora Rural 4. Equipamento de Proteção Individual - EPI. Diário Oficial da União, Brasília, 1988.

BRASIL. Ministério do Trabalho e Emprego. Portaria $\mathrm{n}^{\mathrm{o}} 3.214$, de 8 de junho de 1978 . Norma Regulamentadora 12. Máquinas e Equipamentos.. Diário Oficial da União, Brasília, 1978a.

BRASIL. Ministério do Trabalho e Emprego Portaria ${ }^{\circ} 3.214$, de 8 de junho de 1978 . Norma Regulamentadora 15. Atividades e Operações Insalubres.. Diário Oficial da União, Brasília, 1978b.
ORGANIZAÇÃO INTERNACIONAL DO TRABALHO - OIT. Diretrizes para inspeção do trabalho florestal. Genebra: 2005. 83 p.

OLIVEIRA, P. R. S. Diagnóstico e indicadores de sustentabilidade em fomento florestal no estado do Espírito Santo. 2003. 127f. Dissertação (Mestrado em Ciência Florestal) - Universidade Federal de Viçosa, Viçosa, MG,2003.

QUEIROZ, C. A. R. Manual de terceirização: onde podemos errar no desenvolvimento e na implantação dos projetos e quais são os caminhos do sucesso. São Paulo: STS, 1998. 317p.

RICHARDSON, R. J. Pesquisa social: métodos e técnicas. São Paulo: Altas, 1985. 287p.

SILVA, L.R.W. Análise ergonômica do trabalho em atividades de produção florestal: um estudo comparativo entre o sistema tradicional e o sistema mecanizado. 1995. 137f. Dissertação (Mestrado em Engenharia de Produção) - Universidade Federal de Santa Catarina, Florianópolis, 1995.

SIQUEIRA, J. D. P .et al. Estudo ambiental para os programas de fomento florestal da Aracruz Celulose S.A. e extensão florestal do Governo do Estado do Espírito Santo. Revista Floresta, Edição Especial, p.3-67, 2004. 